\title{
PROCEDIMENTOS DE APO PARA A GESTÃO DE UM EQUIPAMENTO CULTURAL
}

\author{
SILVA, Angela dos Santos
}

Faculdade de Arquitetura e Urbanismo USP, e-mail: angelasilva@usp.br

CONSANI, Camila Pinheiro

Faculdade de Arquitetura e Urbanismo USP, e-mail: camila.consani@usp.br

COUTINHO, Laís de Gusmão

Faculdade de Arquitetura e Urbanismo USP, e-mail: lais.gusmao@usp.br

KAHN, Pamella

Faculdade de Arquitetura e Urbanismo Mackenzie, e-mail: pamella.kahn@gmail.com

MACEDO, Priscila Ferreira

Faculdade de Arquitetura e Urbanismo USP, e-mail: priscilamacedo@usp.br

SANTOS, Reinaldo Luiz dos

Faculdade de Arquitetura e Urbanismo USP, e-mail: Isreinaldo@usp.br

ORNSTEIN, Sheila Walbe

Faculdade de Arquitetura e Urbanismo USP, e-mail: sheilawo@usp.br

\begin{abstract}
RESUMO
Este artigo, resultante de disciplina da pós-graduação realizada em 2018, na Faculdade de Arquitetura e Urbanismo da Universidade de São Paulo, teve como estudo de caso dois edifícios de grande porte que abrigam um equipamento cultural relevante localizado na capital paulista. Verificou-se o desempenho físico de ambos e a satisfação de seus usuários, utilizando conceitos e instrumentos que norteiam a Avaliação Pós-Ocupação (APO). Realizou-se um walkthrough para reconhecimento e anotações preliminares, que embasaram a elaboração dos instrumentos utilizados: questionários com os visitantes; medições para elaboração do as built, checklists sobre três temas (manifestações patológicas, acessibilidade e segurança contra incêndio) e entrevistas com funcionários. Verificou-se que a inexistência de um plano diretor para a gestão da manutenção e da operação contribuiu para a intensificação dos problemas construtivos e funcionais encontrados no decorrer da vida útil dos edifícios. Os diagnósticos e as recomendações elaborados, a partir da comparação "avaliadores versus usuários", propiciaram o desenvolvimento de quadros e mapas detalhados sobre estes aspectos. Estes resultados poderão auxiliar tanto pesquisadores que se utilizam da APO na organização sistêmica de dados, como profissionais que realizam a gestão de equipamentos culturais e necessitam de planos diretores ou orientativos para tomarem as decisões sobre a manutenção e a readequação construtiva e funcional desses edifícios.
\end{abstract}

Palavras-chave: Equipamento cultural, Avaliação pós-ocupação, Instrumentos.

\section{ABSTRACT}

This article is based on a study done in 2018 for a graduate discipline at School of Architecture and Urbanism (FAUUSP), and had as study case two large buildings that are part of a relevant cultural centre in Sao Paulo City. The physical performance and users' satisfaction of both buildings were verified using concepts and tools that guide the Post-Occupancy Evaluation (POE). A walkthrough was conducted for reconnaissance and preliminary notes, which were the basement for the development of the research tools: a questionnaire with visitors, measurement

SILVA, A. S.; CONSANI, C. P.; COUTINHO, L. G.; KAHN, P.; MACEDO, P. F.; SANTOS, R. L.; ORNSTEIN, S. W. Procedimentos de APO para a gestão de um equipamento cultural. In: SIMPÓSIO BRASILEIRO DE QUALIDADE DO PROJETO NO AMBIENTE CONSTRUÍDO, 6., 2019, Uberlândia. Anais... Uberlândia: PPGAU/FAUeD/UFU, 2019. p. 1318-1327. DOI https://doi.org/10.14393/sbqp19119. 
for the as built design; checklists about three themes (pathological manifestations, accessibility and fire safety) and interviews with some staff members. It was confirmed that the lack of a maintenance and operation master plan contributed for the reinforcement of the constructive and functional problems that were found out. The diagnosis and recommendations drafted from the comparison among evaluators versus users point of views provided the development of detailed tables and maps with need improvements and positive aspects. The tables and maps can support researcheres that use POE study as data systemic organization and also professionals of cultural centre management that need a strategic or guiding plan to make decisions about maintenance, operation and constructive and functional buildings readjustment.

Keywords: Cultural Centre, Post-Occupancy Evaluation (POE), Tools.

\section{INTRODUÇÃO}

A gestão de manutenção e operação de edifícios envolve diferentes procedimentos de avaliação que se iniciam desde a etapa de concepção de projeto até a operação, o uso e a manutenção dos edifícios. De acordo com a Associação Brasileira dos escritórios de Arquitetura (AsBea), a criação da ABNT NBR 15.575 (2013), ao agregar uma extensa relação de normas das mais diversas disciplinas relacionadas ao tema, estabeleceu ampla e solidária junção de incumbências entre os intervenientes do processo, reafirmando a importância das discussões sobre o desempenho do ambiente construído no âmbito da construção civil. A APO possui grande relevância neste assunto, a partir do momento que esta ciência se preocupa em entender como um edifício funciona após sua construção e o quanto os ambientes criados atendem às expectativas dos usuários (FEDERAL FACILITIES COUNCIL, 2001). Sobre o desempenho, Rheingantz et al. (2009) afirmam que através da APO seria possível avaliar a influência e as consequências das decisões projetuais no ambiente construído, a partir da consideração dos aspectos relacionados ao uso pelos diferentes agentes envolvidos.

Em complemento, tratando-se da conservação e da proteção dos patrimônios edificados, especialmente de equipamentos culturais (EQs), Lopes e Ornstein (2018) apontam a manutenção constante como ação fundamental para a conservação da edificação. Nesse sentido, para avaliar o desempenho de uma edificação patrimonial em uso, este trabalho ampara-se em diretrizes normativas e conceitos da APO e utiliza como estudo de caso um $E Q$, abrangendo dois edifícios, localizados no centro de São Paulo.

Como premissa, é importante saber que o edifício 1 (E1) e o edifício 2 (E2) passaram por diferentes usos ao longo dos anos. Inclusive, foram objeto de obras de adequações de ambientes e de restauro, concluídas no ano de 2018.

O El construído na década de 1930 possui seis pavimentos totalizando $2818 \mathrm{~m}^{2}$ de área construída, com recepção, salas de exposições, salas para cursos e administração, teatro com sua área administrativa e de apoio, vestiários, refeitório para funcionários e biblioteca. Já o E2, reformado recentemente, possui três pavimentos divididos em $1240 \mathrm{~m}^{2}$ de área construída, com salas de exposições, espaço para cafeteria, auditório e áreas de apoio. Os edifícios se conectam no subsolo através de uma praça externa.

O objetivo deste trabalho é destacar a importância da aplicação de diferentes conceitos e instrumentos de APO, de forma a avaliar o desempenho físico dos edifícios e o grau de satisfação de seus usuários, como estratégia na gestão de equipamentos culturais. 


\section{METODOLOGIA}

Os instrumentos de APO aplicados foram previamente definidos de forma a atingir o objetivo deste trabalho. Assim, optou-se pelos instrumentos walkthrough, checklists, além da aplicação de questionários aos visitantes do espaço cultural e entrevistas aos funcionários do local.

\subsection{Walkthrough}

O walkthrough é um instrumento utilizado para reconhecimento do ambiente em estudo, geralmente acompanhado por profissional que conheça as características do edifício. Nesta pesquisa, devido à dimensão do equipamento cultural, a visita guiada foi realizada em dois dias, durante os quais foram feitas anotações sobre os diversos ambientes além de registros fotográficos.

Outras duas visitas foram realizadas aos edifícios a fim de se efetuarem medições para elaboração do as built. De acordo com Villa et al. (2018), os levantamentos físicos são necessários quando não há dados técnicos atualizados sobre 0 ambiente a ser avaliado. Utilizaram-se as trenas convencionais e a laser para compatibilização do projeto.

Analisando as informações coletadas, decidiu-se avaliar, por meio de checklists, os três temas que se sobressaíram durante o walkthrough: acessibilidade, manifestações patológicas e segurança contra incêndio.

\subsection{Checklists para vistoria técnica}

Sobre a acessibilidade, a sua eventual ausência em EQs, pode impedir ou restringir a mobilidade e a autonomia dos usuários, pondo em risco não só a segurança destes, mas também a sua sociabilidade ou aprendizagem. Nesse sentido, o checklist de acessibilidade buscou identificar aspectos positivos e negativos relacionados à acessibilidade nos edifícios, no intuito de contribuir para promover tanto a melhoria da qualidade do ambiente construído, como a consequente democratização do acesso aos locais.

O checklist proposto baseou-se nas normas técnicas vigentes sobre acessibilidade em EQs, quais sejam: NBR 9050 (ABNT, 2015), NBR 16.537 (ABNT, 2016) e à NBR 15.599 (ABNT, 2008). Este instrumento foi aplicado por pavimento e dividiu-se em seis tópicos principais, sendo eles: 1) sinalização e informação; 2) circulação interna, onde são analisados os corredores, desníveis, portas e mobiliários internos; 3) circulação vertical, no qual se avaliam os corrimãos, guarda corpos, escadas, rampas e elevadores; 4) sanitários, banheiros e vestiários, 5) acessos externos; 6) mobiliários e equipamentos urbanos.

O checklist para avaliação das manifestações patológicas foi estruturado levando em consideração que as duas edificações possuem estruturas de épocas distintas, portanto, a avaliação das manifestações patológicas nos edifícios foi analisada separadamente de acordo com as normas vigentes da ABNT e a norma de inspeção predial do Instituto Brasileiro de Avaliações e Perícias de Engenharia do Estado de São Paulo (IBAPE/SP, 2011).

O critério de classificação das anomalias e falhas constatadas em uma inspeção predial considera o risco oferecido aos usuários, ao meio ambiente e ao patrimônio, dentro dos limites de inspeção predial. O grau de risco das 
anomalias e falhas constatadas na Inspeção Predial é classificado como: crítico, regular e mínimo.

A análise do risco consiste na classificação das anomalias e falhas identificadas nos diversos componentes de uma edificação, quanto ao seu grau de urgência, relacionado com fatores de conservação, depreciação, saúde, segurança, funcionalidade, comprometimento de vida útil e perda de desempenho (IBAPE, 2011).

Segundo prática do mercado, a inspeção predial deverá ser planejada conforme o tipo da edificação, consideradas suas características construtivas, qualidade da documentação entregue ao inspetor e nível de inspeção a ser realizado. O planejamento da vistoria deverá ter início com uma entrevista com o responsável da edificação (síndico, administrador ou gestor), com abordagem dos aspectos cotidianos do uso e da manutenção do imóvel.

Com relação às prioridades de inspeção, a norma de inspeção predial sugere o uso de métodos que acabam por determinar os reparos que devem ser realizados com mais urgência, o que indiretamente auxilia na confirmação dos graus de risco. Dentre eles a metodologia "Gravidade (G), Urgência (U) e Tendência (T)" (GUT), mas sem a definição de seus critérios (VERZOLA et al., 2014), desenvolvida por Kepner Tregoe, em 1977.

Para a avaliação, o sistema dispõe do uso de pesos que são destinados a classificação de cada item inspecionado, a fim de definir graus de criticidade em relação aos problemas encontrados. As notas são atribuídas de 1 a 10 , sendo 1 o menos grave. Ao final da atribuição de notas para os problemas é calculado o produto $(G) \times(U) \times(T)$. $O$ resultado definirá qual o grau de prioridade daquele problema para intervenção (VERZOLA et al., 2014).

A lista de verificação para a inspeção predial desenvolvida para este estudo foi também fundamentada no Guia da Boa Manutenção do IBAPE/SP (2009).

O checklist completo foi dividido em oito tabelas para cada sistema subdivididas de acordo com os elementos que a compõem. Os sistemas escolhidos foram: elementos estruturais, vedações, revestimentos, esquadrias, coberturas, reservatórios, instalações e mecanizações.

Para o levantamento das manifestações patológicas durante as vistorias foi proposto um checklist organizado em uma planilha de prioridades para cada edifício. Na planilha apresentava-se o sistema, o elemento, o componente e qual manifestação patológica foi encontrada durante as vistorias, sempre separados por pavimentos e acompanhados da localização e foto.

Na mesma planilha, na coluna "prioridade" encontrava-se a classificação final do grau de prioridade do problema para intervenção. Para melhor compreensão e padronização, as manifestações patológicas com a pontuação já calculada pelo Método GUT foram classificadas da seguinte maneira: quando resultar em gravidade será considerado grau de risco crítico, quando resultar em urgência será considerado grau de risco regular e quando resultar em tendência será considerado grau de risco mínimo.

O checklist para avaliação da segurança contra incêndio do centro universitário foi estruturado considerando as instruções técnicas (IT) vigentes do Corpo de Bombeiros da Polícia Militar do Estado de São Paulo (CBPMESP, 2018). 
Para iniciar a elaboração do checklist, foram classificados os dois edifícios que compõem o EQ quanto ao tipo de ocupação e altura, de acordo com o que está estipulado no artigo 22 do Decreto Estadual n 56.819 (SÃO PAULO, 2011). Assim, temos que o El apresenta ambientes do tipo F-1 (galerias e exposições) e F-5 (auditórios e espaços cênicos), além de possuir uma altura média (entre 12 e 23 metros). O E2 também apresenta ambientes F-1 e F-5, e é classificado como uma construção de baixa-média altura (entre 6 e 12 metros).

Considerando que O El foi construído antes da vigência do decreto, as exigências mínimas a serem atendidas são estipuladas pela IT $n^{\circ}$ 43: Adaptação às normas de segurança contra incêndio - Edificações existentes (CBPMESP, 2018): iluminação e sinalização de emergência, alarme de incêndio, instalações elétricas, brigada de incêndio, hidrantes, saída de emergência, selagem de shafts e dutos, controle de material de acabamento e revestimento. O E2 por ter sido recentemente reformado, deve atender às exigências atuais do CBPMESP.

Devido ao tempo hábil para execução do trabalho, e pela dimensão e complexidade do equipamento cultural, optou-se por padronizar as exigências utilizadas para avaliação de ambos os edifícios. Verificaram-se, portanto, somente aquelas estipuladas para $\mathrm{O} E \mathrm{l}$, com exceção da verificação da selagem dos shafts e do controle de materiais e revestimentos.

\subsection{Questionário}

O questionário é um instrumento de avaliação aplicado para coletar informações quantitativas sobre os usuários de um local relativamente a pontos de interesse do avaliador. Em APO aplicada em EQs, este instrumento, dentre outros, afere o grau de satisfação de visitantes em ambientes construídos e possibilita a elaboração de recomendações e intervenções no edifício.

Foram aplicados questionários durante uma semana do mês de maio de 2018 no E2, visto que nesse momento apresentava uma exposição relevante ao meio acadêmico. O uso da ferramenta Google Forms auxiliou na estruturação deste instrumento e na sua aplicação, realizada por meio de aparelho celular e tablet. Além disso, processa as respostas e as apresenta por meio de gráficos.

As questões foram divididas em seis áreas: dados sociais, relação com a vizinhança, funcionalidade e comunicação visual, segurança, conforto ambiental e percepção sobre os edifícios. Houve questões com escala de valores (ótimo, bom, regular, ruim e péssimo), de múltipla escolha (sim, não e não sei), e abertas com resposta curta.

O nível de confiança e a margem de erro foram obtidos através do método de amostragem probabilística aleatória simples, na qual cada elemento da população-alvo tem a mesma chance de ser selecionado. Considerando a média mensal de 593 visitantes do ano 2017, dado mais recente disponível, para alcançar um grau de confiança de $95 \%$ e margem de erro de $5 \%$ deveriam ser aplicados os questionários em 400 pessoas. 


\subsection{Entrevista}

Assim como o questionário, a entrevista auxilia na análise do ambiente construído através de informações dadas ao entrevistador sobre a experiência dos usuários de um edifício.

Foram realizadas entrevistas com pessoas-chave, pessoas que detém um amplo conhecimento do funcionamento do Centro Cultural: membros da secretaria, da manutenção, da segurança, do audiovisual e da equipe de cursos. Os pontos levantados com este instrumento abordaram a infraestrutura e a manutenção dos edifícios, além da programação dos eventos realizados.

\section{RESULTADOS E DISCUSSÕES}

Como o estudo proposto abrange uma pesquisa multimétodos, cada instrumento teve sua forma de análise e, consequente, apresentação de seus resultados. Os resultados dos checklists foram organizados em mapas sinópticos e quadro de diagnósticos. As respostas dos questionários foram tabuladas em gráficos sobre o perfil social e os níveis de satisfação dos usuários e as entrevistas foram sistematizadas em textos.

O preenchimento dos checklists, associado ao walkthrough, permitiu a identificação dos problemas por ambiente e a definição do grau de risco de cada um deles. A fim de facilitar a leitura e acepção das informações, os aspectos analisados sobre o desempenho dos edifícios foram divididos, em cores, por eixos temáticos e, em seguida, classificados por grau de risco. Para cada tema, adotou-se uma cor (verde, laranja e azul) e cada cor variou de intensidade de acordo com seu grau do risco, quanto maior o risco, mais escura a coloração (Quadro 1).

Quadro 1 - Cores adotadas por eixo temático

\begin{tabular}{|c|c|c|c|}
\hline \multirow{2}{*}{ Eixo temático } & \multicolumn{2}{|c|}{ Grau de Risco } \\
\cline { 2 - 4 } & Mínimo & Regular & Crítico \\
\hline Manifestações Patológicas & & & \\
\hline Acessibilidade & & & \\
\hline Segurança contra incêndio & & & \\
\hline
\end{tabular}

Fonte: Autores (2019)

Os resultados desses procedimentos metodológicos foram sintetizados em um quadro de diagnósticos, dividido por pavimento. Cada quadro continha 0 eixo temático do qual fazia parte a ocorrência, a localização dela e o seu tipo, seguido pelas normas utilizadas como referência para identificação do problema, o grau de risco e as recomendações de ajustes propostas. Um exemplo de cada tema pode ser visto no Quadro 2.

Ao final, as informações dos quadros sinópticos foram transpostas para as plantas baixas de cada pavimento, formando os mapas sinópticos por pavimentos. Para cada ocorrência, foram inseridos, por ambiente, círculos coloridos que, seguindo o padrão de cores e intensidade definidos, indicavam visualmente, em planta, o eixo temático do problema e o seu grau risco (Figura 1). 
Quadro 2 - Exemplo de quadro sinóptico

\begin{tabular}{|c|c|c|c|c|c|}
\hline \multicolumn{6}{|c|}{ E1 - $3^{\circ}$ Pavimento } \\
\hline $\begin{array}{c}\text { Eixo } \\
\text { temático }\end{array}$ & Localização & Tipo & Norma & $\begin{array}{c}\text { Grau de } \\
\text { Risco }\end{array}$ & Recomendação \\
\hline 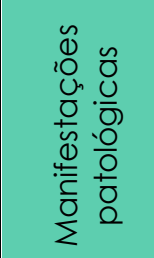 & - Sacada & $\begin{array}{l}\text { - Lâmpadas } \\
\text { queimadas e } \\
\text { QDLF externo }\end{array}$ & $\begin{array}{l}\text { IBAPE/SP } \\
(2011)\end{array}$ & Crítico & $\begin{array}{l}\text { - Trocar luminárias e lâmpadas, } \\
\text { colocar modelos específicos } \\
\text { para área externa } \\
\text { - Proteger e trocar modelo de } \\
\text { QDLF }\end{array}$ \\
\hline 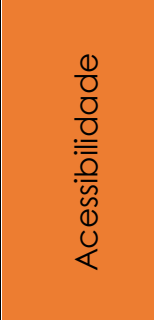 & $\begin{array}{l}\text { - Hall e } \\
\text { circulação }\end{array}$ & $\begin{array}{l}\text {-Ausência de } \\
\text { sinalização } \\
\text { tátil ou } \\
\text { sonora } \\
\text { associada à } \\
\text { visual nas } \\
\text { passagens e } \\
\text { portas }\end{array}$ & $\begin{array}{c}\text { NBR } \\
9050 \\
\text { (ABNT, } \\
2015)\end{array}$ & Mínimo & $\begin{array}{l}\text { - Incluir sinalização tátil de piso } \\
\text { direcional (alerta em mudanças } \\
\text { de direção), a partir do elevador } \\
\text { direcionando aos espaços } \\
\text { expositivos ou incluir mapa tátil } \\
\text { para localização dos espaços } \\
\text { expositivos e demais ambientes. }\end{array}$ \\
\hline 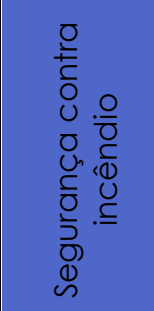 & - Geral & $\begin{array}{l}\text { - Ausência de } \\
\text { iluminação } \\
\text { de } \\
\text { emergência }\end{array}$ & $\mathrm{IT} \mathrm{n} \mathrm{n}^{\circ} 18$ & Crítico & $\begin{array}{l}\text { - Instalar sistema de iluminação } \\
\text { de emergência }\end{array}$ \\
\hline
\end{tabular}

Fonte: Adaptado de Silva et al. (2018)

Alguns ambientes ou sistemas, como, o telhado e a caixa-d'água, não puderam ser acessados, logo não foram avaliados. Apesar disso, os resultados das avaliações técnicas indicaram a existência de problemas de desempenho no $E Q$ em todos os pavimentos, em ambos os edifícios e em graus distintos. Em geral, as ocorrências encontradas foram ocasionadas por recursos financeiros limitados e a inexistência de um plano estratégico de manutenção. Os resultados obtidos também demonstram que a vida útil dos edifícios não tem uma influência determinante no desempenho de um EQ, posto que, apesar da diferença no ano de construção entre o El e O E2, ambos apresentaram problemas e riscos semelhantes.

Os resultados das entrevistas, por sua vez, revelaram as limitações do EQ em estudo no atendimento a eventos maiores e nas suas demandas de manutenção, especialmente no que se refere às instalações elétricas, na área dos funcionários e no controle contra vandalismo na área externa.

Nos questionários, a maioria dos respondentes sentiu falta de um espaço para alimentação (café), mais espaços de descanso e implantação de uma livraria. Sobre os aspectos relacionados ao ambiente construído, a maioria dos 
respondentes avaliou positivamente (bom e ótimo) a experiência no EQ, com exceção da sinalização que foi avaliada, principalmente, entre bom e regular.

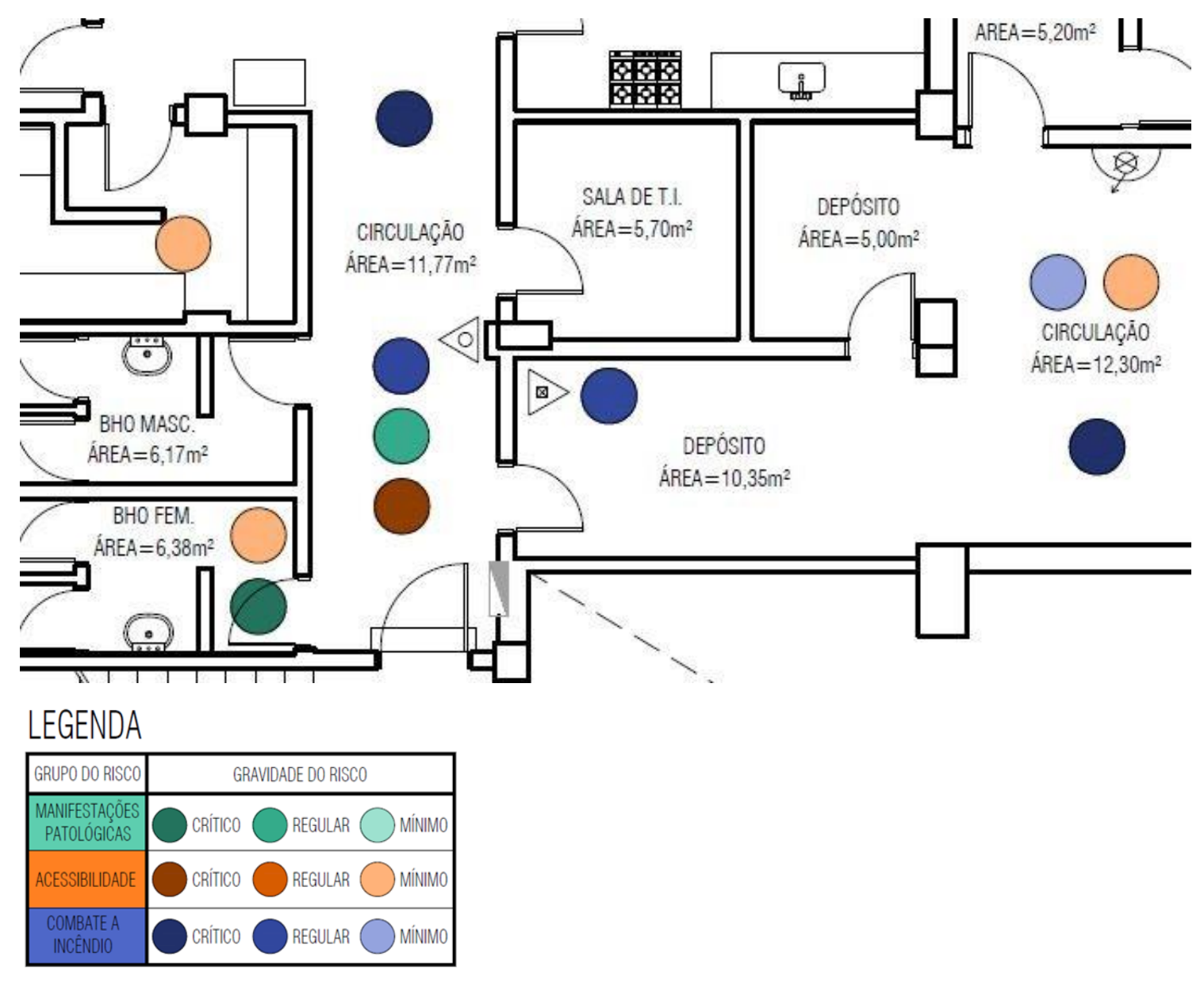

Figura 1 - Exemplo de mapa sinóptico -

Fonte: SILVA et al. (2018)

As pessoas que responderam aos questionários e que foram entrevistadas assinaram um termo de consentimento livre e esclarecido em que foi autorizado o uso das respostas neste estudo acadêmico.

Devido ao pouco tempo para aplicação de questionários e ao baixo número de visitantes no período, um total de 59 pessoas, não foi possível atingir a quantidade de questionários previstos no plano amostral, anteriormente mencionado. Também não foi possível realizar pré-teste, impossibilitando a reformulação de questões que não se apresentarem inteligíveis durante a aplicação.

Apesar de os dados não serem exaustivos, algumas discussões a respeito do uso dos instrumentos de APO como estratégia de gestão podem ser definidas. O uso de gráficos, quadro de recomendações e mapas sinópticos facilita a visualização das ocorrências encontradas, como, a ausência de iluminação e sinalização de emergência em caso de incêndio e de alguns itens de acessibilidade. Destaca-se, portanto, que o diagnóstico proposto fornece um panorama de fácil compreensão sobre a situação do $E Q$, podendo se configurar em um importante documento a ser utilizado pela equipe gestora, visto que a sistematização dos dados em formas de representação simples 
facilita a compreensão e a visualização das ocorrências por todos os agentes envolvidos no processo de gestão do EQ.

Além disso, os diferentes instrumentos de APO, ao serem utilizados na avaliação das diferentes edificações em uso, permitem, para além da identificação dos problemas, a proposição de recomendações para readequações espaciais e outras intervenções físicas que podem ser utilizadas como referência para a elaboração de um plano de manutenção de EQs. A partir das análises e diagnósticos propostos, a equipe gestora consegue definir com mais precisão, não apenas a urgência de algumas intervenções, mas também quantificar as etapas das diversas demandas, sejam estas emergenciais ou não. E por fim, aferir se as necessidades dos usuários estão sendo efetivamente atendidas e qual o seu grau de satisfação.

\section{CONSIDERAÇÕES FINAIS}

Ao se avaliar os aspectos construtivos, de segurança contra incêndio e de acessibilidade, constatou-se que as especificações técnicas necessárias para garantir um desempenho adequado dos edifícios, em alguns casos foram atendidas parcialmente, mas em outros foram desconsideradas. Portanto, reforça-se a necessidade de adequação às normas e legislações vigentes, além da elaboração de um plano de gestão e manutenção para o EQ.

A aplicação da APO pode se transformar em importante ferramenta estratégica para a realização da gestão de edifícios, fornecendo subsídios para organização sistêmica de dados, e elaboração de planos diretores ou orientativos necessários para o aprimoramento da qualidade do ambiente construído, principalmente no que se refere a edifícios de caráter histórico que alteraram seus usos ao longo do tempo.

Dessa forma, conclui-se que a avaliação do desempenho dos edifícios, tanto do ponto de vista do ambiente construído, como da percepção de satisfação dos usuários, gerou um produto que pode se constituir num conjunto de procedimentos para fundamentar a tomada de decisões da equipe gestora.

\section{AGRADECIMENTOS}

À equipe do EQ e ao Conselho Nacional de Desenvolvimento Científico e Tecnológico ( $\mathrm{CNPq}$ ) pela bolsa produtividade concedida à Sheila Walbe Ornstein.

\section{REFERÊNCIAS}

ASSOCIAÇÃO BRASILEIRA DE NORMAS TÉCNICAS (ABNT). NBR 15575:

Edificações Habitacionais - Desempenho. Rio de Janeiro, 2013.

. NBR 15999: Acessibilidade - Comunicação na prestação de serviços. $1^{a}$ ed. Rio de Janeiro: ABNT, 2008.

. NBR 9050: Acessibilidade a edificações, mobiliário, espaços e equipamentos urbanos. $3^{a}$ ed. Rio de Janeiro, 2015.

NBR 16537: Acessibilidade - Sinalização tátil no piso - Diretrizes para elaboração de projetos e instalação. $1^{a}$ ed. Rio de Janeiro: ABNT, 2016. 
ASSOCIAÇÃO BRASILEIRA DOS ESCRITÓRIOS DE ARQUITETURA (AsBEA). Guia para arquitetos na aplicação da norma de desempenho ABNT NBR 15575. São Paulo: AsBEA, s/d. Disponível em: <http://www.asbea.org.br/manuais>. Acesso em: 20 mai. 2019.

CORPO DE BOMBEIROS DA POLÍCIA MILITAR DO ESTADO DE SÃO PAULO (CBPMESP). Instrução técnica $n^{\circ}$ 43: Adaptação às normas de segurança contra incêndio - Edificações existentes. São Paulo, 2018.

FEDERAL FACILITIES COUNCIL. Learning from our Buildings: A State-of-thePractice Summary of Post-Occupancy Evaluation. Washington, DC: National Academy Press, 2001. (Federal Facilities Technical Report No 145). Disponível em: <https://www.nap.edu/read/10288/chapter/1>. Acesso em: 28 mai. 2019.

INSTITUTO BRASILEIRO DE AVALIAÇÕES E PERÍCIAS DE ENGENHARIA DE SÃO PAULO (IBAPE/SP). Inspeção predial: check-up predial: guia de boa manutenção. 2. Ed. São Paulo: Liv. e Ed. Universitária de Direito, 2009.

. Norma de Inspeção Predial. São Paulo, 2011 . Disponível em:

<http://www.ibape-sp.org.br/arquivos/norma_de_inspecao_predial.pdf>. Acesso em: 15 mai. 2018.

LOPES, S.; ORNSTEIN, S. O Potencial da Avaliação Pós-Ocupação (APO) para a Preservação de Ambientes Museológicos Localizados em Edifícios Antigos: O Caso do Museu da Imigração, SP. Revista Projetar - Projeto e Percepção do Ambiente, v. 3, n. 2, p. 67-79, 29 ago. 2018. Disponível em: <https://periodicos.ufrn.br/revprojetar/article/view/16547>. Acesso em: 03 fev. 2019.

RHEINGANTZ, P. A.; AZEVEDO, G.; BRASILEIRO, A.; ALCANTARA, D.; QUEIROZ, M. Observando a qualidade do lugar: procedimentos para a avaliação pósocupação. Rio de Janeiro: Universidade Federal do Rio de Janeiro, Faculdade de Arquitetura e Urbanismo, Pós- Graduação em Arquitetura, 2009. Disponível em: <http://www.gae.fau.ufrj.br/assets/obs_a_qua_lugar.pdf>. Acesso em: 03 de fev. de 2019.

SÃO PAULO (Estado). Decreto $\mathbf{n}^{\circ} \mathbf{5 6 . 8 1 9}$, de 10 de março de 2011. Institui o Regulamento de Segurança contra Incêndio das edificações e áreas de risco no Estado de São Paulo e estabelece outras providências. São Paulo, 2011.

SILVA, A. S. et al. Avaliação pós-ocupação do conjunto edificado de um equipamento cultural. 183f. Trabalho de conclusão de disciplina (Pósgraduação) - Faculdade de Arquitetura e Urbanismo da Universidade de São Paulo (FAUUSP), São Paulo, 2018.

VERZOLA, S. N.; MARCHIORI, F. F.; ARAGON, J. O. Proposta de lista de verificação para inspeção predial x urgência das manutenções. ENTAC - XV Encontro Nacional de Tecnologia do Ambiente Construído. Anais... Maceió, 2014. Disponível em:

<http://www.infohab.org.br/entac2014/artigos/paper_300.pdf>. Acesso em: 15 mai. 2018.

VILLA, S. B. et al. Procedimentos Metodológicos. In: ONO, R. et al. Avaliação pós-ocupação na arquitetura, no urbanismo e no design: da teoria à prática. São Paulo: Oficina de Textos, 2018. Cap.4. p. 81-94. 